\title{
COMPARISON OF COMPONENTS PROFILE IN HERBAL RAW MATERIAL, EXTRACT AND PHARMACEUTICALS OF HEDERA HELIX
}

\author{
I. Bezruk, V. Georgiyants, L. Ivanauskas
}

The aim. To investigate both the profile of components and possible difference among herbal raw materials, semi-products and pharmaceuticals of Hedera helix for determination of main standartisation markers.

Materials and methods. Investigation of components profile has been performed using the Shimadzu Nexera $X 2$ chromatographic system coupled with a diode-area detector. The ACE C 18 column $(250 \mathrm{~mm} \times 4.6 \mathrm{~mm}$ with particle size $5 \mu \mathrm{m}$ ) was used for the separation of components. $0.1 \%$ acetic acid and acetonitrile were used as mobile phase $A$ and B, respectively. Studies have been performed on the leaves, dry extract and capsules of H. helix.

Results. The determined profile had no significant variation among samples. It has been presented by 19 various components, such as phenolic acids, flavonoids and triterpene saponins. However, kaempferol, nicotiflorin and t-cinnamic acid were not found in the leaf raw material. Hederacoside $C$ might be highlighted as the main marker of raw materials and products of $H$. helix due to its significant amount in comparison to other components. Its amount was in the range of 64,80\% up to 71,46\% of the total content of components. Moreover, according to some pharmacological studies, hederacoside $C$ is responsible for pharmaceutical usage of $H$. helix pharmaceutics. Nevertheless, it is not recommended to standardize the plant-based medicines by one marker, since the pharmaceutical activity of such dosage forms is defined by synergism action of all constituents. Except for hederacoside $C$ significant amounts in comparison to other components were found for chlorogenic acid and 4,5dicaffeoylquinic acid about $5 \%$ and $3 \%$ respectively. Though the latter was found in small concentrations in leaves (0,058\%). This sample had a much higher amount of 3,5-dicaffeoylquinic acid, but in the case of extract and capsules, its content was lower 1,55\% and 0,66\% respectively. Thus, chlorogenic acid has been chosen as a second marker due to its high concentration in all samples and some pharmaceutical activities, such as antioxidant and anti-inflammatory effects.

Conclusions. It was found, that standartisation of $H$. helix products is preferably to perform with determination both hederacoside $C$ and chlorogenic acid. These components were dominant among all components; besides they possess a wide range of pharmaceutical effects. Hence, quantification of hederacoside $C$ and chlorogenic acid is necessary to ensure the high quality of $H$. helix pharmaceuticals.

Keywords: ivy leaf, components profile, pharmaceuticals, extracts, HPLC

Copyright (C) 2020, I. Bezruk, V. Georgiyants, L. Ivanauskas. This is an open access article under the CC BY license (http://creativecommons.org/licenses/by/4.0).

\section{Introduction}

Plant-based medicines have a significant part of the pharmaceutical market in the whole world. It is a well-known fact that plant extracts show some advantages over synthetic pharmaceutics due to the synergism of plant constituents [1]. However, the standartisation of herbal medicines is usually determined by macroscopic and microscopic examination with the following assay of the main biomarker [2, 3]. In particular, the quality of $H$. helix leaves, as well as medicines, are confirmed by quantification of hederacoside C. Nevertheless, medicinal plants contain various groups of biologically active components with different pharmacological effects [4]. Hence, the pharmacological activity is often caused by the synergic effect of phytoconstituents mixture [5]. Therefore, standartisation of plant-based medicines with a couple of biomarkers might provide higher quality and efficacy [6]. Another crucial moment is to choose the markers which can be suitable for the assessment of both raw materials and pharmaceuticals.
The aim of the research was to determine the profile of raw materials and medicines of $H$. helix and found components that can be used as markers for the standartisation.

\section{Planning (methodology) of research}

The State Pharmacopoeia of Ukraine requires the determination of hederacoside for the assessment of $H$. helix products [7, 8]. However, it is known that plantbased medicines contain various components that might show the synergism of their pharmaceutical activities. Hence standartisation of such pharmaceutics only by one marker is not recommended. The present study included the following stages: analysis of $H$. helix leaves, extract, and capsules by HPLC and comparison of their profiles to determine the possible markers for standartisation.

\section{Material and methods}

Analysis has been performed using according to Gluschenko, Mykhailenko and Bezruk [9-11] with Shimadzu Nexera X2 chromatographic system coupled with 
the diode-array detector. Column ACE C18 (250 mm $\times$ $\times 4,6 \mathrm{~mm}$ with particle size $5 \mu \mathrm{m}$ ) was used in the analysis. $0.1 \%$ acetic acid and acetonitrile were used as mobile phase $\mathrm{A}$ and $\mathrm{B}$, respectively. A linear gradient was as follows: 0-8 $\mathrm{min}, 5-15 \% \mathrm{~B}$; 8-30 $\mathrm{min}, 15-20 \% \mathrm{~B}$; 30-48 min, 20-40 \% B; 48-58 min, 40-50 \% B; 58-65 min, $50 \% \mathrm{~B}$; 65-66 min, 50-95\% B at a flow rate of $1 \mathrm{ml} / \mathrm{min}$. The column oven was at $25^{\circ} \mathrm{C}$. The injection of the test solution (standard solution) was $10 \mu \mathrm{l}$.

Test solution of leaves. The solution was prepared as described in Bezruk et al. [11]. Briefly, precisely weighed $1.0 \mathrm{~g}$ of $H$. helix leaves were extracted in triplicate with $15 \mathrm{ml}$ of methanol by ultrasound bath for 15 minutes. Obtained supernatants were combined and made up to $50 \mathrm{ml}$ with methanol.

Test solution for capsules. $400 \mathrm{mg}$ precisely weighted capsule powder were placed into $20.0 \mathrm{~mL}$ volumetric flask, added $15 \mathrm{~mL}$ of methanol and sonicated for 20 minutes on the ultrasonicated bath at the ambient temperature. After the solution was let cool, it was made up to volume with the same solution.

Test solution for dry extract. $200 \mathrm{mg}$ precise weighted extract were placed into $20.0 \mathrm{~mL}$ volumetric flask, add $15 \mathrm{~mL}$ of methanol and sonicated for 20 minutes on the ultrasonicated bath at the ambient temperature after the solution was let cool, it was made up to volume with the same solution.

\section{Results}

Obtained results showed the presence of 19 various components, such as phenolic acids, flavonoids and triterpene saponins. All of the components were present in each sample, except t-cinnamic acid, kaempferol and nicotiflorin which were not found in leaves. The triterpene saponins were the dominant components in all samples (Table 1-3). Their concentration was about $70 \%$ of the total quantitative amount in each sample. Mostly, the contents of triterpene saponins were in the following order: hederacoside $\mathrm{C}>$ hederacoside $\mathrm{D}>\alpha$-hederin $>$ hederasaponin B. Greunke et al. reported about the importance of $\alpha$-hederin and hederasaponin B [12]. Among all constituents, hederacoside $\mathrm{C}$ was the dominant component. Its concentration was in the range of $63973.701 \pm 19.677$ up to $149433.64 \pm 852.86$ which was about $70 \%$ of the total content of all components. Moreover, hederacoside $\mathrm{C}$ is essential due to its transformation into $\alpha$-hederin in the human body [13]. The second greatest group was phenolic acids. They contribute to pharmaceutical effects [12]. Among them, the most significant amount was for chlorogenic acid and 4,5dicaffeoylquinic acid about $5 \%$ and $3 \%$ respectively. Caffeoylquinic acid derivates are established as being responsible for anti-inflammatory and antioxidant effects [14]. Though 4,5-dicaffeoylquinic acid was present in a small concentration in leaves $(52,04 \pm 2.59 \mu \mathrm{g} / \mathrm{g})$. This sample had a much higher amount of 3,5dicaffeoylquinic acid $(2904.445 \pm 143.27 \mu \mathrm{g} / \mathrm{g})$, but in the case of extract and capsules, its contents were lower $1489.07 \pm 73.68$ and $178.35 \pm 8.87$ respectively. Thus, the chlorogenic acid can be highlighted as the second biomarker in H. helix due to its high amount in each sample. Also, chlorogenic acid shows anti-inflammatory activity [15] which can be beneficial in the treatment of acute respiratory diseases.

Table 1

Content of phenolic acids (mean \pm SD) in Hedera helix samples

\begin{tabular}{|l|c|c|c|}
\hline \multicolumn{1}{|c|}{ Object } & Capsules & Extract & Leaves \\
\hline Gallic acid & $8.70 \pm 0.34$ & $86.31 \pm 2.65$ & $12.30 \pm 0.15$ \\
\hline Neochlorogenic acid & $105.81 \pm 2.57$ & $2145.15 \pm 54.52$ & $92.104 \pm 1.41$ \\
\hline Chlorogenic acid & $494.59 \pm 14.92$ & $10539.29 \pm 234.69$ & $4838.402 \pm 23.21$ \\
\hline t-Cinnamic acid & $0.56 \pm 0.02$ & $0.21 \pm 0.01$ & $\mathrm{n} / \mathrm{d}$ \\
\hline Caffeic acid & $6.93 \pm 0.16$ & $146.35 \pm 5.57$ & $74.503 \pm 2.73$ \\
\hline 3,5-dicaffeoylquinic acid & $178.35 \pm 8.87$ & $1489.07 \pm 73.68$ & $2904.445 \pm 143.27$ \\
\hline 3,4-dicaffeoylquinic acid & $279.81 \pm 13.72$ & $2151.32 \pm 105.76$ & $365.402 \pm 15.02$ \\
\hline 4,5-dicaffeoylquinic acid & $569.47 \pm 27.61$ & $4700.32 \pm 219.57$ & $52.04 \pm 2.59$ \\
\hline Cryptochlorogenic acid & $143.82 \pm 7.07$ & $3698.14 \pm 179.36$ & $13.576 \pm 0.627$ \\
\hline
\end{tabular}

Table 2

Content of flavonoids (mean \pm SD) in Hedera helix samples

\begin{tabular}{|l|c|c|c|}
\hline \multicolumn{1}{|c|}{ Object } & Capsules & Extract & Leaves \\
\hline Quercitin & $49.12 \pm 1.54$ & $897.15 \pm 24.57$ & $2.471 \pm 0.132$ \\
\hline Kaempferol & $7.35 \pm 0.29$ & $133.32 \pm 2.57$ & $\mathrm{n} / \mathrm{d}$ \\
\hline Rutin & $9.46 \pm 0.34$ & $176.42 \pm 3.81$ & $57.101 \pm 1.558$ \\
\hline Hyperoside & $403.39 \pm 16.09$ & $7752.61 \pm 18.36$ & $3266.802 \pm 13.364$ \\
\hline Isoquercitrin & $8.48 \pm 0.24$ & $190.46 \pm 5.39$ & $39.000 \pm 0.952$ \\
\hline Nicotiflorin & $16.68 \pm 0.82$ & $54.49 \pm 2.69$ & $\mathrm{n} / \mathrm{d}$ \\
\hline
\end{tabular}

Table 3

Content of triterpene saponins (mean \pm SD) in Hedera helix samples

\begin{tabular}{|l|c|c|c|}
\hline \multicolumn{1}{|c|}{ Object } & Capsules & Extract & Leaves \\
\hline Hederacoside C & $7447.41 \pm 253.24$ & $149433.64 \pm 852.86$ & $63973.701 \pm 19.677$ \\
\hline$\alpha$-hederin & $555.93 \pm 19.74$ & $10505.21 \pm 26.26$ & $249.604 \pm 26.482$ \\
\hline Hederasaponin B & $261.14 \pm 13.01$ & $3612.05 \pm 176.35$ & $2762.240 \pm 109.052$ \\
\hline Hederacoside D & $946.86 \pm 46.53$ & $26441.31 \pm 1324.07$ & $10825.469 \pm 537.835$ \\
\hline
\end{tabular}




\section{Discussions}

Results of performed studies have complied with previously conducted researches [16, 17]. Yu et al. [16] found chlorogenic acid, rutin, nicotiflorin, hederacoside $\mathrm{C}$, hederasaponin $\mathrm{B}$ and $\alpha$-hederin in ivy leaf extracts using HPLC-DAD method. Except for rutin content, its results have completely corresponded to the ones in this article. Probably $\mathrm{Yu}$ et al. misidentified rutin instead of hyperoside. In this case, further investigations should be carried out to highlight hyperoside as a marker in Hedera helix products since it has a significant amount in all analysed samples.

According to Demirci et al., the most important markers for standartisation of ivy leaf are hederacoside $\mathrm{C}$ and $\alpha$-hederin [17]. This seems logical since, as it was above mentioned, hederacoside $\mathrm{C}$ transforms into $\alpha$ hederin which is responsible for pharmaceutical usage of $H$. helix pharmaceuticals. However, the level of $\alpha$-hederin showed no stability due to some variation in content in studied samples. Thus, it is not advisable to use this component for standartisation of $H$. helix products.

In addition, Khadar et. al [18] recommended standardising medicines containing ivy leaf extract by quantification of hederacoside $\mathrm{C}$. In our opinion, it is the most optimum decision due to the fact that hederacoside $\mathrm{C}$ was the dominant substance in all studied samples.
Study limitations. The profile of components in ivy is presented by various constituents the content of which significantly varied. Hence the determination of the main biomarkers is a complicated task. Besides during the preparations either dry extract or medicine some substance might reduce their concentration.

Prospects for further research. The obtained data might be used in the standardization and quality assurance of pharmaceuticals containing $H$. helix leaf extract.

\section{Conclusions}

Analysis of $H$. helix leaves, extract and capsules showed the presence of various components. Some of them possess pharmacological activities which can cause the synergism of effects. Hederacoside $\mathrm{C}$ and chlorogenic acid had a dominant concentration among all components. Also, both of them contribute the beneficial pharmaceutical effects to cure bronchitis and cold accompanied by cough and sputum. Hence, medicines of $H$. helix might standardize using hederacoside $\mathrm{C}$ and chlorogenic acid to deliver effective and safe pharmaceutics for patients.

\section{Conflict of interest}

There are no conflicts of interest regarding this study.

\section{References}

1. Obiageri, O. (2012). Pharmacokinetics and Drug Interactions of Herbal Medicines: A Missing Critical Step in the Phytomedicine/Drug Development Process. Readings in Advanced Pharmacokinetics - Theory, Methods and Applications. doi: http://doi.org/10.5772/33699

2. Tistaert, C., Dejaegher, B., Heyden, Y. V. (2011). Chromatographic separation techniques and data handling methods for herbal fingerprints: A review. Analytica Chimica Acta, 690 (2), 148-161. doi: http://doi.org/10.1016/j.aca.2011.02.023

3. Guo, D. (2017). Quality Marker Concept Inspires the Quality Research of Traditional Chinese Medicines. Chinese Herbal Medicines, 9 (1), 1-2. doi: http://doi.org/10.1016/s1674-6384(17)60069-8

4. Edeoga, H. O., Okwu, D. E., Mbaebie, B. O. (2005). Phytochemical constituents of some Nigerian medicinal plants. African Journal of Biotechnology, 4 (7), 685-688. doi: http://doi.org/10.5897/ajb2005.000-3127

5. Muthuselvam, S. A. (2009). Analysis of phytochemical constituents and antimicrobial activities of aloe vera L. against clinical pathogens. World Journal of Agriculture and Soil Science, 5 (5), 572-576.

6. European Pharmacopoeia (2019). Available at: https://www.edqm.eu/en/european-pharmacopoeia-ph-eur-10th-edition

7. Derzhavna Pharmakopeya Ukrayini. Vol. 1. DP «Naukovo-ekspertniy farmakopeyniy tsentr» (2015). Kharkiv: DP «Ukrayinskiy naukoviy farmakopeyniy tsentr yakostI lIkarskih zasobIv», 1128.

8. Bezruk, I., Kotvitska, A., Korzh, I., Materiienko, A., Gubar, S., Budanova, L. et. al. (2020). Combined Approach to the Choice of Chromatographic Methods for Routine Determination of Hederacoside C in Ivy Leaf Extracts, Capsules, and Syrup. Scientia Pharmaceutica, 88 (2), 24. doi: http://doi.org/10.3390/scipharm88020024

9. Glushchenko, A., Bezruk, I., Bevz, N., Ivanauskas, L., Georgiyants, V. (2019). Development of the procedure of quantitative determination of the biological active substances in the extract of a bupleurum aureum in the composition of a combined dosage form. ScienceRise: Pharmaceutical Science, 1 (17), 11-16. doi: http://doi.org/10.15587/2519-4852.2019.157947

10. Mykhailenko, O., Gudžinskas, Z., Kovalyov, V., Desenko, V., Ivanauskas, L., Bezruk, I., Georgiyants, V. (2020). Effect of ecological factors on the accumulation of phenolic compounds in Iris species from Latvia, Lithuania and Ukraine. Phytochemical Analysis, 31 (5), 545-563. doi: http://doi.org/10.1002/pca.2918

11. Bezruk, I., Marksa, M., Georgiyants, V., Ivanauskas, L., Raudone, L. (2020). Phytogeographical profiling of ivy leaf (Hedera helix L.). Industrial Crops and Products, 154, 112713. doi: http://doi.org/10.1016/j.indcrop.2020.112713

12. Greunke, C., Hage-Hülsmann, A., Sorkalla, T., Keksel, N., Häberlein, F., Häberlein, H. (2015). A systematic study on the influence of the main ingredients of an ivy leaves dry extract on the $\beta 2$-adrenergic responsiveness of human airway smooth muscle cells. Pulmonary Pharmacology \& Therapeutics, 31, 92-98. doi: http://doi.org/10.1016/j.pupt.2014.09.002

13. Schmidt, O. (2003). Biopharmazeutische Charakterisierung von Efeublattertrockenextrakten durch in vivo und in vitro Studien (Dissertation). Heidelberg: Ruprecht-Karls-Universiat.

14. Naveed, M., Hejazi, V., Abbas, M., Kamboh, A. A., Khan, G. J., Shumzaid, M. et. al. (2018). Chlorogenic acid (CGA): A pharmacological review and call for further research. Biomedicine \& Pharmacotherapy, 97, 67-74. doi: http://doi.org/10.1016/j.biopha.2017.10.064 
15. Kim, H.-R., Lee, D.-M., Lee, S.-H., Seong, A.-R., Gin, D.-W., Hwang, J.-A., Park, J.-H. (2010). Chlorogenic acid suppresses pulmonary eosinophilia, IgE production, and Th2-type cytokine production in an ovalbumin-induced allergic asthma: Activation of STAT-6 and JNK is inhibited by chlorogenic acid. International Immunopharmacology, 10 (10), 1242-1248. doi: http://doi.org/10.1016/j.intimp.2010.07.005

16. Yu, M., Shin, Y. J., Kim, N., Yoo, G., Park, S., Kim, S. H. (2014). Determination of Saponins and Flavonoids in Ivy Leaf Extracts Using HPLC-DAD. Journal of Chromatographic Science, 53 (4), 478-483. doi: http://doi.org/10.1093/chromsci/bmu068

17. Demirci, B., Goppel, M., Demirci, F., Gerhard, F. (2004). HPLC profiling and quantification of active principles in leaves of Hedera helix L. Die Pharmazie, 59, 770-774.

18. Khdair, A., Mohammad, M. K., Tawaha, K., Al-Hamarsheh, E., AlKhatib, H. S., Al-khalidi Bashar et. al. (2010). A Validated RP HPLC-PAD Method for the Determination of Hederacoside C in Ivy-Thyme Cough Syrup. International Journal of Analytical Chemistry, 2010, 1-5. doi: http://doi.org/10.1155/2010/478143

Received date 10.06.2020

Accepted date 08.07.2020

Published date 31.08.2020

Ivan Bezruk, Postgtaduate Student, Department of Pharmaceutical Chemistry, National University of Pharmacy, Pushkinska str., 53, Kharkiv, Ukraine, 61002

E-mail: vania.bezruk@gmail.com

Victoriya Georgiyants, Doctor of Pharmaceutical Sciences, Professor, Head of Department, Department of Pharmaceutical Chemistry, National University of Pharmacy, Pushkinska str., 53, Kharkiv, Ukraine, 61002

E-mail:vgeor@ukr.net

Liudas Ivanauskas, Doctor of Biomedical Sciences, Professor, Head of Department, Department of Analytical and Toxicological Chemistry, Lithuanian University of Health Sciences, Mickevičiaus g. 9, Kaunas, Lithuania, LT 44307

E-mail: liudas.ivanauskas@1smuni.lt 